\title{
Estimation of Cerebral Venous Saturation in Newborn Infants by Near Infrared Spectroscopy
}

\author{
L. SKOV, O. PRYDS, G. GREISEN, AND H. LOU \\ Department of Neonatology, State University Hospital (Rigshospitalet), Copenhagen, Denmark
}

\begin{abstract}
The purpose of the study was to evaluate the near infrared spectroscopy technique for determination of the cerebral venous oxygen saturation. By tilting the patient's head down $15^{\circ}$, changes in OD may be caused by changes in cerebral blood volume. On the assumption that increases in cerebral blood volume consist of venous blood only, cerebral venous oxygen saturation can be calculated as the measured change in oxygenated $\mathrm{Hb}$ divided by the change in total $\mathrm{Hb}$. Two groups of mechanically ventilated, newborn infants were investigated: 10 asphyxiated, term infants and another 22 preterm infants with respiratory distress syndrome. All were monitored by near infrared spectroscopy during tilting, and cerebral blood flow was estimated by the ${ }^{133} \mathrm{Xe}$ clearance technique immediately before tilting. Cerebral venous oxygen saturation could not be calculated in 13 preterm infants, as the blood volume remained constant during tilting. In the remaining 19, cerebral venous oxygen saturation averaged $0.67(\mathrm{SD}=$ 0.09 ) in asphyxiated infants and $0.53(\mathrm{SD}=0.15)$ in preterm infants $(p=0.03)$. The corresponding values of cerebral blood flow were closely and inversely related to oxygen extraction calculated from cerebral venous saturation as estimated by near infrared spectroscopy. (Pediatr Res 33: 52-55, 1993)
\end{abstract}

Abbreviations

CBF, cerebral blood flow $(\mathrm{mL} / 100 \mathrm{~g} / \mathrm{min})$

$\mathrm{CBV}$, cerebral blood volume $(\mathrm{mL} / \mathbf{1 0 0} \mathrm{g})$

$\mathrm{CMRO}_{2}$, cerebral metabolic rate of $\mathrm{O}_{2}\left(\mathrm{~mL} \mathrm{O}_{2} / 100 \mathrm{~g} / \mathrm{min}\right)$

MABP, mean arterial blood pressure

NIRS, near infrared spectroscopy

COD, cerebral oxygen delivery $(\mathrm{mL} / 100 \mathrm{~g} / \mathrm{min})$

$\mathrm{OE}$, oxygen extraction $\left(\mathrm{mL} \mathrm{O}_{2} / 100 \mathrm{~g} / \mathrm{min}\right)$

$\mathrm{SaO}_{2}$, arterial saturation

$\mathrm{CSvO}_{2}$, cerebral mixed venous saturation

$\mathrm{HbO}_{2}$, oxygenated hemoglobin

deoxy-Hb, deoxygenated hemoglobin

$\mathrm{PaO}_{2}$, arterial oxygen tension

$\mathrm{PaCO}_{2}$, arterial carbon dioxide tension

In at least two situations, it would be valuable to have information on $\mathrm{CSvO}_{2}$ in the sick, newborn infant. Very low levels of $\mathrm{CBF}$ have been found among mechanically ventilated, preterm infants, and these infants may be at high risk of ischemic brain lesions (1). When CBF is low, however, the brain may escape from ischemia by enhancing the $\mathrm{OE}$ from the blood, resulting in low $\mathrm{CSvO}_{2}$ values. Conversely, $\mathrm{CBF}$ is markedly elevated after

Received January 2, 1992; accepted September 1, 1992.

Correspondence: L. Skov, Department of Neonatology, Rigshospitalet, Blegdamsvej, 2100 Copenhagen $\varnothing$, Denmark.

Supported by the G. and A. Haench Foundation and the Dagmar Marshall Foundation. severe birth asphyxia (2). In this hyperperfusion state, a high $\mathrm{CSvO}_{2}$ would represent "luxury perfusion," indicating serious brain damage (3), whereas a normal $\mathrm{CSvO}_{2}$ might demonstrate an intact coupling between $\mathrm{CBF}$ and the metabolic needs.

It is not practical to sample cerebral venous blood, e.g. from the internal jugular vein, in view of the invasive nature of the technique (4). Recently, it has been suggested that the cerebral venous oxygen content can be estimated noninvasively by NIRS (5).

The purpose of this study was to evaluate whether the estimated $\mathrm{CSvO}_{2}$ was related to the simultaneously measured CBF.

\section{MATERIALS AND METHODS}

Patients. Two groups of mechanically ventilated, newborn infants were investigated: 10 asphyxiated, term infants with umbilical cord pH less than 7.10 and/or a 5-min Apgar score less than 5 and another 22 preterm infants with respiratory distress syndrome (Table 1).

NIRS. NIRS depends on the relative transparency of the neonate's head to near infrared light. The light is attenuated by scattering and absorption in the tissues. Our NIRS instrument (Radiometer, Copenhagen, Denmark) uses four semiconductor laser diodes with wavelengths of $775,805,845$, and $904 \mathrm{~nm}$. The lasers are operated sequentially and pulsed for 200 ns with a repetition rate of $500 \mathrm{~Hz}$. Optical fiber bundles are used to transmit and receive the light $(6,7)$. In the present study, the NIRS recordings were performed in transmission mode in lowbirth-weight infants, whereas larger infants were investigated in reflection mode. In both modes, the relation between optical path length and interoptode spacing appears to be constant, as recently observed in time-of-flight studies (8). The calculation of $\mathrm{CSvO}_{2}$ does not require any information on the optical path length, as $\mathrm{CSvO}_{2}$ is expressed in fractions. Conversely, the optical path length must be known for the calculation of changes in CBV (Table 1). Significant changes in CBV were required for estimation of $\mathrm{CSvO}_{2}$, and $\mathrm{CBV}$ was calculated as previously suggested (9). We assumed that the optical light path length is $4.4 \times$ the interoptode distance (10).

Estimation of $\mathrm{CSvO}_{2}$. $\mathrm{CSvO}_{2}$ was estimated by tilting the infant head-down $15^{\circ}$. The acute alterations in the cerebral concentration of $\mathrm{HbO}_{2}$ and deoxy-Hb that result from tilting may be assumed to be caused by an increase in venous blood only. By comparing the incremental changes in $\mathrm{HbO}_{2}$ and deoxy- $\mathrm{Hb}$, $\mathrm{CSvO}_{2}$ can be calculated from the formula:

$$
\mathrm{CSvO}_{2}=\Delta\left(\mathrm{HbO}_{2}\right) / \Delta\left[\left(\mathrm{HbO}_{2}\right)+(\text { deoxy- } \mathrm{Hb})\right]
$$

where $\mathrm{CSvO}_{2}$ is expressed as a fraction. $\mathrm{CSvO}_{2}$ was derived from stable 90 -s periods before and during tilting.

$C B F$. CBF was measured by the ${ }^{133} \mathrm{Xe}$ clearance technique, as previously described (11). Briefly, $20-40 \mathrm{MBq} / \mathrm{kg}{ }^{133} \mathrm{Xe}$ were injected into a peripheral vein, and the clearance was recorded by scintillation detectors placed over one frontoparietal region and the thorax, respectively. A recording time of $15 \mathrm{~min}$ was 
Table 1. Comparison of physiologic data between preterm infants and asphyxiated term infants*

\begin{tabular}{|c|c|c|c|c|}
\hline & \multicolumn{2}{|c|}{ Preterm } & \multirow[b]{2}{*}{$\begin{array}{c}\text { Term } \\
(n=10)\end{array}$} & \multirow[b]{2}{*}{$p$} \\
\hline & $\begin{array}{c}\text { Nonreacting } \\
(n=13)\end{array}$ & $\begin{array}{c}\text { Reacting } \\
(n=9)\end{array}$ & & \\
\hline Gestational age (wk) & $27.9(1.7)^{\mathrm{b}}$ & $29.4(2.2)^{\mathrm{a}}$ & $38.1(1.1)^{\mathrm{a}, \mathrm{b}}$ & $<0.0001$ \\
\hline Postnatal age $(\mathrm{h})$ & $22.8(16.0)$ & $32.0(16.4)^{b}$ & $15.7(8.2)^{b}$ & 0.06 \\
\hline $\mathrm{FiO}_{2}$ & $0.41(0.10)$ & $0.53(0.25)$ & $0.49(0.23)$ & 0.35 \\
\hline $\mathrm{PaO}_{2}(\mathrm{kPa})$ & $8.9(1.6)$ & $10.3(3.0)$ & $9.6(2.2)$ & 0.41 \\
\hline $\mathrm{PaCO}_{2}(\mathrm{kPa})$ & $4.9(1.6)$ & $4.1(1.0)$ & $4.0(0.6)$ & 0.15 \\
\hline $\mathrm{SaO}_{2}$ & $0.97(0.04)$ & $0.96(0.05)$ & $0.94(7.0)$ & 0.42 \\
\hline $\mathrm{Hb}(\mathrm{mM})$ & $9.0(1.5)$ & $9.9(1.4)$ & $10.3(1.9)$ & 0.13 \\
\hline $\mathrm{CBF}(\mathrm{mL} / 100 \mathrm{~g} / \mathrm{min})$ & $11.1(3.9)^{\mathrm{a}}$ & $12.6(6.4)^{\mathrm{b}}$ & $26.5(17.9)^{\mathrm{a}, \mathrm{b}}$ & 0.005 \\
\hline $\mathrm{CBV}$ change $(\mathrm{mL} / 100 \mathrm{~g})$ & & $0.13(0.08)$ & $0.16(0.07)$ & 0.37 \\
\hline
\end{tabular}

* Values are mean \pm SD. Preterm infants are grouped according to the response to tilting down. $p$ values are calculated by analysis of variance. $\mathrm{FiO}_{2}$, fraction of inspired oxygen. Superscript letters indicate significant differences between two groups.

used. CBF was calculated from the time when the activity of ${ }^{133} \mathrm{Xe}$ in the lung had decreased to $15 \%$ of the peak activity.

$\mathrm{COD}$ was calculated as the product of physically dissolved and $\mathrm{Hb}$-bound $\mathrm{O}_{2}$ and $\mathrm{CBF}$ :

$$
\begin{gathered}
\mathrm{COD}=\left[\left(\mathrm{PaO}_{2} \times 0.227+\mathrm{SaO}_{2} \times 21.0 \times \mathrm{Hb}\right) / 1000\right] \\
\times \mathrm{CBF} \mathrm{mL} \mathrm{O} / 100 \mathrm{~g} / \mathrm{min}
\end{gathered}
$$

$\mathrm{SaO}_{2}$ was measured by pulse oximetry (Datex, Helsinki, Finland). MABP was recorded from an indwelling umbilical catheter, and the transducer was kept at heart level.

Study design. CBF and $\mathrm{CSvO}_{2}$ were measured after the infant had been undisturbed for at least $30 \mathrm{~min}$. At the end of the CBF measurement, the infant was tilted head-down for a 3-min period and he or she was subsequently returned to horizontal level. Arterial blood was drawn for analysis of blood gases (ABL, Radiometer), $\mathrm{Hb}$ concentration, and oxygen saturation (OSM3, Radiometer). It was assumed that $\mathrm{CBF}$ and oxygen consumption remained constant during the tilting maneuver.

Statistics. Linear regression analysis and analysis of variance were used when appropriate. Multiple comparisons between groups were performed by the Student-Newman-Keuls procedure.

The study was approved by the Ethics Committee for Greater Copenkagen, and parental informed consent was obtained for each infant.

\section{RESULTS}

Response to tilting. A marked and significant increment in CBV in response to tilting was observed in 19 infants. However, in 13 of the 22 preterm infants, CBV did not respond significantly during the procedure. Apparently, these nonreacting preterm infants required lower ventilatory rates compared with the nine reacting preterm infants, whereas other parameters were identical (Table 1). The nonreacting infants were excluded from the following calculations.

In reacting infants, the response to tilting appeared within 15 to $20 \mathrm{~s}$ with an increase in $\mathrm{HbO}_{2}$, and deoxy- $\mathrm{Hb}$, and hence in CBV. These variables returned to baseline levels when the infant was returned to the horizontal position (Fig. 1). The increase in CBV was identical in asphyxiated, term infants and preterm infants (Table 1), and these changes were not statistically related to changes in MABP or to the $\mathrm{PaCO}_{2}$ level.

$\mathrm{CSvO}_{2}$ and $\mathrm{CBF}$. In all infants, $\mathrm{CSvO}_{2}$ ranged from 0.30 to

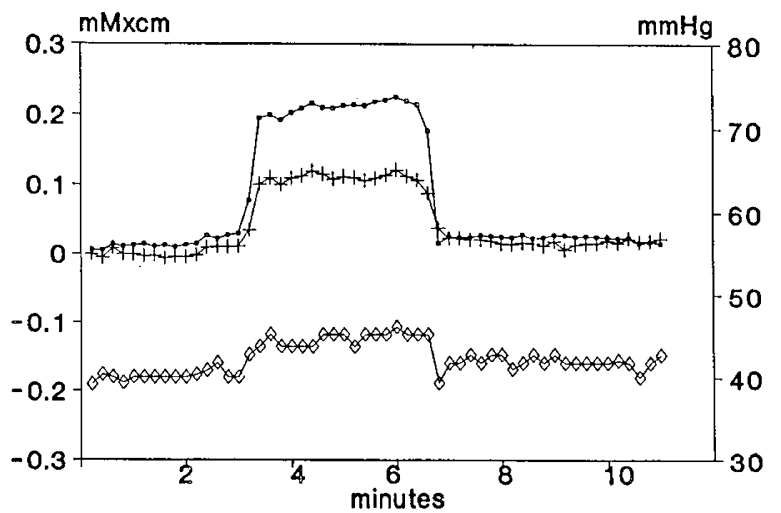

Fig. 1. Changes in cerebral concentration of $\mathrm{CBV}(\mathbf{m})$, oxyhemoglobin $(+)$, and $\mathrm{MABP}(\diamond)$ in response to tilting in a preterm infant. $\mathrm{CBF}=18$ $\mathrm{mL} / 100 \mathrm{~g} / \mathrm{min}, \mathrm{CSvO}_{2}=0.61$.

0.80 (mean 0.61), whereas CBF averaged $19.9 \mathrm{~mL} / 100 \mathrm{~g} / \mathrm{min}$ (range 5.1-60.5). $\mathrm{CSvO}_{2}$ as well as $\mathrm{CBF}$ were higher in the asphyxiated, term infants compared with preterm infants with respiratory distress (Table 1). $\mathrm{CSvO}_{2}$ was not related to the level of $\mathrm{PaCO}_{2}$ or $\mathrm{PaO}_{2}$.

$O E, C O D$, and $\mathrm{CMRO}_{2}$. OE, calculated as the product of blood $\mathrm{Hb}$ concentration and difference between $\mathrm{SaO}_{2}$ and $\mathrm{CSvO}_{2}$, was significantly higher in preterm infants than in asphyxiated, term infants (Table 1). Despite interindividual variation, $\mathrm{CSvO}_{2}$ was curvilinearly related to $\mathrm{COD}$, with a high slope at low COD levels and a plateau at higher levels (Fig. 2). Similarly, an apparent linear relationship was observed between OE and $1 / \mathrm{CBF}(P<0.001)$, where the slope $(\mathrm{OE} \times \mathrm{CBF})$ represents $\mathrm{CMRO}_{2}$ (Fig. 3). $\mathrm{CMRO}_{2}$ was identical between the two groups (Table 1).

Case study. Low CBF, low $\mathrm{OE}$, and hence a very low $\mathrm{CMRO}_{2}$ were demonstrated in a term infant with presumed prenatal asphyxia. This infant had an isoelectric EEG, and he died on the 3 rd d of life. Extensive cerebral cystic degeneration, which could be dated to 3-4 wk before delivery, was demonstrated at autopsy, thus explaining the discrepancy between a high $\mathrm{CSvO}_{2}$ and a low CBF.

\section{DISCUSSION}

The increase in CBV during a head-down tilt was significant in the majority of infants allowing calculation of $\mathrm{CSvO}_{2}$. We 


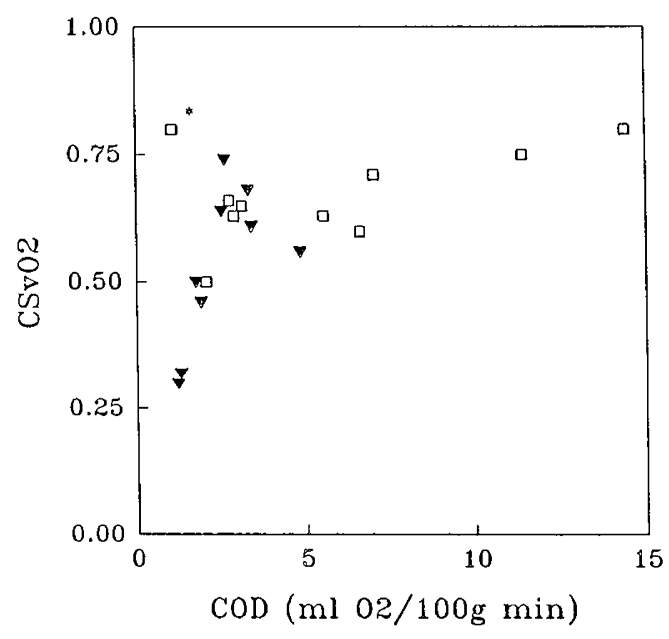

Fig. 2. $\mathrm{CSvO}_{2}$ vs $\mathrm{COD}$ of 19 infants. $\boldsymbol{\nabla}$, preterm infants; $\square$, asphyxiated infants; *, term infant with presumed prenatal asphyxia.

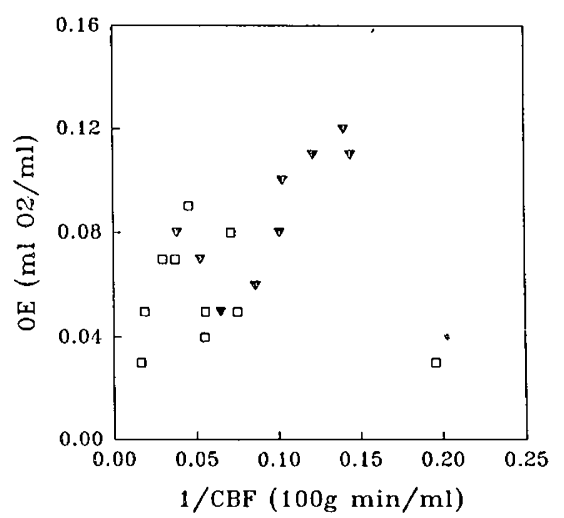

Fig. 3. Cerebral OE vs $1 / \mathrm{CBF}$ of 19 infants. The slope represents $\mathrm{CMRO}_{2}\left(\mathrm{CMRO}_{2}=\mathrm{OE} \times \mathrm{CBF}\right) . \nabla$, preterm infants; $\square$, asphyxiated infants; ${ }^{*}$, term infant with presumed prenatal asphyxia.

have, however, no explanation for why CBV remained constant in 13 preterm infants although the ventilatory rate was lower than that of reacting infants. We did not measure the central venous pressure, and it is possible that high pressures influence changes in CBV during tilting. Another hypothetical explanation is the reactivity of $\mathrm{CBV}$ at different levels of $\mathrm{PaCO}_{2}$ and $\mathrm{PaO}_{2}$, but these variables were similar among reacting and nonreacting infants. Finally, the presence of a venous autoregulatory capacity in the more healthy infants may be relevant (12). Future studies are needed to evaluate whether the failing response is due to biologic or methodologic factors. Besides, the reproducibility of the method should be tested.

There are reasons to believe that $\mathrm{CSvO}_{2}$ was estimated reliably in the reacting infants: 1) $\mathrm{CBV}$ increased rapidly during tilting, thereby indicating a vascular origin; 2) the magnitude of changes of $0.15 \mathrm{~mL} / 100 \mathrm{~g}$ corresponds to $5-10 \%$ of total $\mathrm{CBV}$; and 3 ) the estimated ranges of $\mathrm{CSvO}_{2}$ and $\mathrm{OE}$ are physiologically acceptable.

We recognize that the ideal would have been to examine infants with normal brains in which a normal $\mathrm{CMRO}_{2}$ can be taken for granted. For practical purposes (lack of reaction, excessive movement artifacts), this is not possible. We have reasons, however, to suppose that $\mathrm{CMRO}_{2}$ in the ill infants we studied did not vary markedly: 1) In preterm infants with very low $\mathrm{CBF}$, there are no signs of electrical failure, i.e. no sign of a major decrease in oxygen consumption (13). 2) In asphyxiated term infants with severe asphyxia and very high $\mathrm{CBF}$, an isoelectrical EEG and/or subsequent brain damage indicate that $\mathrm{CMRO}_{2}$ is not increased in parallel. $\mathrm{CMRO}_{2}$ may be somewhat above or even below normal depending on the sum of normal and abnormal metabolic processes occurring during the transformation of the initial insult into cell death and tissue damage. Hence, although the relation between $\mathrm{CSvO}_{2}$ and $\mathrm{CBF}$ cannot be expected to be perfect, it should be sufficient for a preliminary validation to indicate that this method gives physiologically meaningful values. The accuracy of the method must await further studies.

Some possible confounding factors should be considered. An arterial contribution to the increase in CBV during the tilt-down may have occurred though the increases of $\mathrm{CBV}$ were not related to the concomitant changes in MABP. Accurate quantification of $\mathrm{CSvO}_{2}$ requires that the optical path length remains constant during the tilt, and two sources of error are likely to occur in this regard: 1) The increase in CBV may induce a small increase in head circumference and hence an increase in optode distance, and 2) higher cerebral $\mathrm{Hb}$ concentration will increase the $\mathrm{ab}$ sorption. Higher absorption will tend to attenuate photons that have traveled a greater distance, thus shortening the optical path length. Such errors could lead to under- or overestimation of $\mathrm{CSvO}_{2}$. The observed changes in $\mathrm{OD}$ at the four wave lengths could not entirely be explained by changes in $\mathrm{Hb}$ concentrations as the residuals, although small, after having accounted for $\mathrm{Hb}$ nevertheless were systematically different from zero.

Venous saturation has previously been measured in animal experiments using multiwavelength derivative spectroscopy (14), and $\mathrm{CSvO}_{2}$ estimated by this method was in good agreement with the oxygen saturation of blood drawn from the superior sagittal sinus over the range of 0.015 to 0.70 . In that study, the optical fibers were placed directly on the bone over the sagittal sinus with an interoptode distance of $1-2 \mathrm{~cm}$ and hence with a very small sampling volume. It is possible that this method may be adapted to preterm infants in whom the scalp is only a few millimeters thick.

The potential usefulness of measuring $\mathrm{CBF}$ and $\mathrm{CMRO}_{2}$ in infants has already been discussed by Garfunkel et al. in 1954 (15). Three of the 33 infants studied by the nitrous oxide method after internal jugular venous catheterization were newborn (age 2-19 d), and they had very low $\mathrm{CMRO}_{2}$ values (mean $1.5 \mathrm{~mL}$ $\mathrm{O}_{2} / 100 \mathrm{~g} / \mathrm{min}$ ) that actually are comparable to those of the present study, indicating that the absolute values of $\mathrm{CSvO}_{2}$ obtained by NIRS are of the right order of magnitude. This interpretation is supported by the observations of normal neuronal outcome in preterm infants with a very low $\operatorname{CBF}(16,17)$.

Conversely, we found very high $\mathrm{CBF}$ and low $\mathrm{OE}$ in some asphyxiated infants, indicating cerebral luxury perfusion. If the cerebral hyperperfusion was coupled to a high $\mathrm{CMRO}_{2}$, higher $\mathrm{OE}$ values should have been recorded. These results are in agreement with observations by Frewen et al. (18) using the Kety-Schmidt method. The high $\mathrm{CSvO}_{2}$ in one infant with low $\mathrm{CBF}$ and pathologic evidence of past brain injury also supports the accuracy of the $\mathrm{CSvO}_{2}$ measurements.

Conclusion. We suggest that $\mathrm{CSvO}_{2}$ may be estimated in sick newborn infants by NIRS. The ranges of $\mathrm{CSvO}_{2}$ and $\mathrm{OE}$ were physiologically acceptable and closely related to CBF as measured by an independent technique. Future studies are necessary to clarify why the NIRS technique fails in some preterm infants.

\section{REFERENCES}

1. Greisen G 1990 Cerebral blood flow in mechanically ventilated, preterm neonates. Dan Med Bull 2:124-132

2. Pryds O, Greisen G, Lou H, Friis-Hansen B 1990 Vasoparalysis is associated with brain damage in asphyxiated term infants. J Pediatr 117:119-125

3. Lassen N 1966 The luxury-perfusion syndrome and its possible relation to acute metabolic acidosis localised within the brain. Lancet 2:1113-115

4. Settergren G, Lindblad BS, Persson B 1976 Cerebral blood flow and exchange of oxygen, glucose, ketone bodies, lactate, pyruvate and amino acids in infants. Acta Paediatr Scand 65:343-353

5. Wyatt JS, Cope M, Delpy DT, Wray S, Reynolds EOR 1986 Quantification of cerebral oxygenation and haemodynamics in sick newborn infants by near infrared spectrophotometry. Lancet 8515:1063-1066

6. Rea PA, Crowe J, Wickramasinghe Y, Rolfe P 1985 Non-invasive optical 
methods for the study of cerebral metabolism in the human newborn: a technique for the future? J Med Eng Tech 9:160-166

7. Pryds O, Greisen G, Skov LL, Friis-Hansen B 1990 The effect of $\mathrm{PaCO}_{2}$ induced increase in cerebral blood volume and cerebral blood flow in mechanically ventilated, preterm infants. Comparison of near infra-red spectrophotometry and ${ }^{133}$ Xenon clearance. Pediatr Res 27:445-449

8. van der Zee P, Cope M, Arridge SR, Essenpreis M, Potter LA, Edwards AD, McCormick DC, Roth SC, Reynolds EOR, Delpy DT 1992 Experimentally measured optical pathlengths for the adult head, calf and forearm and the head of the newborn infant as a function of inter optode spacing. Adv Exp Med (in press)

9. Wyatt JS, Cope M, Delpy DT, Richardson CE, Edwards AD, Wray S, Reynolds EOR 1990 Quantitation of cerebral blood volume in human infants by nearinfrared spectroscopy. J Appl Physiol 68:1086-1091

10. Wray S, Cope M, Delpy DT, Wyatt JS, Reynolds EOR 1988 Characterization of the near infrared absorption spectra of cytochrome aa3 and haemoglobin for the non-invasive monitoring of cerebral oxygenation. Biochim Biophys Acta 933:184-192

11. Greisen G and Pryds O 1988 Intravenous 133 Xe clearance in preterm neonates with respiratory distress. Internal validation of $\mathrm{CBF} \infty$ as a measure of global cerebral blood flow. Scand J Clin Lab Invest 48:673-678
12. Skov L, Pryds O, Greisen G, Lou H 1991 Cerebral mixed venous saturation and cerebral blood flow. 4th International Conference on fetal and neonatal physiological measurements. Rotterdam Maj, p 304(abstr)

13. Pryds O, Greisen G 1990 Preservation of single-flash visual evoked potentials at very low cerebral oxygen delivery in preterm infants. Pediatr Neurol $6: 151-158$

14. Ferrari M, Wilson DA, Hanley DF, Hartmann JF, Rogers MC, Traystman RJ 1989 Noninvasive determination of hemoglobin saturation in dogs by derivative near-infrared spectroscopy. Am J Physiol 256:H1493-H1499

15. Garfunkel JM, Baird HW, Ziegler J 1954 The relationship of oxygen consumption to cerebral functional activity. J Pediatr 44:64-72

16. Altman DI, Powers WJ, Perlman JF, Herscovitch P, Volpe SL, Volpe JJ 1988 Cerebral blood flow requirement for brain viability in newborn infants is lower than in Adults. Ann Neurol 24:218-226

17. Altman DI, Perlman JM, Volpe JJ, Powers WJ 1989 Cerebral oxygen metabolism in newborn infants measured with position emission tomography. $\mathrm{J}$ Cereb Flow Metab 9:s25(abstr)

18. Frewen TC, Kissoon N, Kronick J, Fox M, Lee R, Bradwin N, Chance G 1991 Cerebral blood flow, cross-brain oxygen extraction, and fontanelle pressure after hypoxic-ischemic injury in newborn infants. J Pediatr 118:265-271

\section{Announcements}

\section{Annual Meetings}

The American Pediatric Society, The Society for Pediatric Research, and The Ambulatory Pediatric Association will hold their annual meetings May 3-6, 1993 at the Sheraton Washington Hotel, Washington, DC. For further information, contact: APS/SPR Association Headquarters, 141 Northwest Point Blvd., P.O. Box 675, Elk Grove Village, IL 60009-0675, (708) 427-0250, FAX (708) 427-1305 or Ambulatory Pediatric Association, 6728 Old McLean Village, McLean, VA 22101, (703) 556-9222, FAX (703) 556-8729.

\section{Call for Abstracts}

The Society for Behavioral Pediatrics will conduct its 11 th Annual Scientific Meeting on September 12-13, 1993 at the Providence Marriott in Providence, RI. We invite you to submit abstracts of research papers for consideration for presentation at the scientific sessions. ABSTRACTS MUST BE RECEIVED BY MARCH 1, 1993. For further information and abstract forms, please contact Ms. Noreen Spota at (215) 248-9168. 
methods for the study of cerebral metabolism in the human newborn: a technique for the future? J Med Eng Tech 9:160-166

7. Pryds O, Greisen G, Skov LL, Friis-Hansen B 1990 The effect of $\mathrm{PaCO}_{2}$ induced increase in cerebral blood volume and cerebral blood flow in mechanically ventilated, preterm infants. Comparison of near infra-red spectrophotometry and ${ }^{133}$ Xenon clearance. Pediatr Res 27:445-449

8. van der Zee P, Cope M, Arridge SR, Essenpreis M, Potter LA, Edwards AD, McCormick DC, Roth SC, Reynolds EOR, Delpy DT 1992 Experimentally measured optical pathlengths for the adult head, calf and forearm and the head of the newborn infant as a function of inter optode spacing. Adv Exp Med (in press)

9. Wyatt JS, Cope M, Delpy DT, Richardson CE, Edwards AD, Wray S, Reynolds EOR 1990 Quantitation of cerebral blood volume in human infants by nearinfrared spectroscopy. J Appl Physiol 68:1086-1091

10. Wray S, Cope M, Delpy DT, Wyatt JS, Reynolds EOR 1988 Characterization of the near infrared absorption spectra of cytochrome aa3 and haemoglobin for the non-invasive monitoring of cerebral oxygenation. Biochim Biophys Acta 933:184-192

11. Greisen G and Pryds O 1988 Intravenous 133 Xe clearance in preterm neonates with respiratory distress. Internal validation of $\mathrm{CBF} \infty$ as a measure of global cerebral blood flow. Scand J Clin Lab Invest 48:673-678
12. Skov L, Pryds O, Greisen G, Lou H 1991 Cerebral mixed venous saturation and cerebral blood flow. 4th International Conference on fetal and neonatal physiological measurements. Rotterdam Maj, p 304(abstr)

13. Pryds O, Greisen G 1990 Preservation of single-flash visual evoked potentials at very low cerebral oxygen delivery in preterm infants. Pediatr Neurol $6: 151-158$

14. Ferrari M, Wilson DA, Hanley DF, Hartmann JF, Rogers MC, Traystman RJ 1989 Noninvasive determination of hemoglobin saturation in dogs by derivative near-infrared spectroscopy. Am J Physiol 256:H1493-H1499

15. Garfunkel JM, Baird HW, Ziegler J 1954 The relationship of oxygen consumption to cerebral functional activity. J Pediatr 44:64-72

16. Altman DI, Powers WJ, Perlman JF, Herscovitch P, Volpe SL, Volpe JJ 1988 Cerebral blood flow requirement for brain viability in newborn infants is lower than in Adults. Ann Neurol 24:218-226

17. Altman DI, Perlman JM, Volpe JJ, Powers WJ 1989 Cerebral oxygen metabolism in newborn infants measured with position emission tomography. $J$ Cereb Flow Metab 9:s25(abstr)

18. Frewen TC, Kissoon N, Kronick J, Fox M, Lee R, Bradwin N, Chance G 1991 Cerebral blood flow, cross-brain oxygen extraction, and fontanelle pressure after hypoxic-ischemic injury in newborn infants. J Pediatr 118:265-271

\section{Announcements}

\section{Annual Meetings}

The American Pediatric Society, The Society for Pediatric Research, and The Ambulatory Pediatric Association will hold their annual meetings May 3-6, 1993 at the Sheraton Washington Hotel, Washington, DC. For further information, contact: APS/SPR Association Headquarters, 141 Northwest Point Blvd., P.O. Box 675, Elk Grove Village, IL 60009-0675, (708) 427-0250, FAX (708) 427-1305 or Ambulatory Pediatric Association, 6728 Old McLean Village, McLean, VA 22101, (703) 556-9222, FAX (703) 556-8729.

\section{Call for Abstracts}

The Society for Behavioral Pediatrics will conduct its 11 th Annual Scientific Meeting on September 12-13, 1993 at the Providence Marriott in Providence, RI. We invite you to submit abstracts of research papers for consideration for presentation at the scientific sessions. ABSTRACTS MUST BE RECEIVED BY MARCH 1, 1993. For further information and abstract forms, please contact Ms. Noreen Spota at (215) 248-9168. 